Acta Oceanol. Sin., 2018

DOI: $10.1007 /$ s13131-018-1275-4

http://www.hyxb.org.cn

E-mail: hyxbe@263.net

\title{
Erratum to: Relationships between intensity of the Kuroshio current in the East China Sea and the East Asian winter \\ monsoon
}

YIN Ming ${ }^{1,3}$, LI Xin ${ }^{2,3}$, XIAO Ziniu², LI Chongyin ${ }^{2,3}$

${ }^{1}$ Army 61936 of PLA, Haikou 571100, China

${ }^{2}$ Institute of Atmospheric Physics, Chinese Academy of Sciences, Beijing 100029, China

${ }^{3}$ Institute of Meteorology \& Oceanography, National University of Defense Technology, Nanjing 211101, China

Received 16 August 2017; accepted 26 September 2017

(C) Chinese Society for Oceanography and Springer-Verlag GmbH Germany, part of Springer Nature 2018

Erratum to: Acta Oceanologica Sinica, 2018, Vol. 37, No. 7, P. 8-19, https://doi.org/10.1007/s13131-018-1240-2

Due to the negligence of the author, the third affiliation and address "Institute of Meteorology and Oceanography, The Army Engineering University of PLA, Nanjing 211101, China” in the originally published article version was not correct, and should be changed to "Institute of Meteorology \& Oceanography, National University of Defense Technology, Nanjing 211101, China", hereby certify.

The online version of the original article can be found at https://doi.org/10.1007/s13131-018-1240-2 